\title{
Aluízio Pinheiro Ferreira: Maçonaria, Revolução de 30 e a criação do Território Federal do Guaporé
}

\section{Aluízio Pinheiro Ferreira: Freemasonry, the 1930 Revolution and the creation of the Federal Territory of Guapore in Brazil}

Dante Ribeiro da Fonseca

Fundación Universidad Federal de Rondônia, Brasil zeliafonseca@brturbo.com.br

Recepción: 25 de julio de 2019/Aceptación: 30 de agosto de 2019

doi: https://doi.org/10.15517/rehmlac.v11i2.37470

\section{Palavras-chave}

Aluízio Pinheiro Ferreira; Maçonaria; Revolução; Guaporé; Território Federal.

\section{Keywords}

Aluízio Pinheiro Ferreira, Freemasonry, Revolution, Federal Territory, Guapore.

\section{Resumo}

O artigo aborda a biografia de Aluizio Pinheiro Ferreira durante o período que vai de 1897 até 1943. Enfatiza dois aspectos da vida do biografado: sua atividade pública e sua filiação maçônic, tendo como pano de fundo principal a Revolução de 30 (1930 - 1945) e a cisão da Maçonaria Brasileira (1927). O período culmina com a criação do Território Federal do Guaporé (hoje estado brasileiro de Rondônia) em 1943, no período mais duro do governo de exceção (1937 a 1945), e a nomeação de Aluizio Ferreira como seu primeiro governador.

\section{Abstract}

The article discusses the biography of Aluizio Pinheiro Ferreira from 1897 to 1943. It emphasizes two features of his lifetime: his public activity and his Masonic affiliation, during the 1930 Revolution (1930-1945) and the secession of Brazilian Freemasonry (1927). The period culminated with the creation of the Federal Territory of Guaporé (now the state of Rondônia) in 1943, during harshest period of the government of exception (1937 to 1945), and the appointment of Aluizio Ferreira as Rondônia's first governor. 


\section{Introdução}

O presente trabalho é um resumo de parte da pesquisa acadêmica ainda não publicada que desenvolvo, intitulada: “O Território Federal do Guaporé (1943 - 1981)”, que trata da História dessa unidade da federação brasileira.

O estado de Rondônia (anteriormente Território Federal do Guaporé), fica situado no centro da América do Sul, ao Noroeste do Brasil, mais propriamente na região Norte. Faz fronteira com a Bolívia e tem sua história caracterizada pela ocupação de parte da bacia dos rios Madeira, Mamoré e Guaporé pelos colonizadores luso brasileiros entre os séculos XVII e XIX. Mais tarde, já no século XX, foram colonizadas as áreas atualmente cortadas pela rodovia BR-364, também denominada Cuiabá-Porto Velho. O traçado dessa rodovia segue, com algumas alterações, a picada aberta para a instalação da linha telegráfica de Cuiabá a Porto Velho na segunda década do século XX.

O rio Guaporé nasce no Mato Grosso e corre para o norte até formar o rio Mamoré. Os formadores do rio Madeira: os rios Mamoré e Beni, nascem no interior da Bolívia. O rio Mamoré ao receber as águas do rio Guaporé (cujo nome na Bolívia é Itenez) segue com a denominação de Mamoré, até juntar-se ao rio Beni, formando a nascente do rio Madeira, que tem sua foz no rio Amazonas. Seus afluentes principais: o Jamari, o Ji-Paraná (ou Machado) e o Candeias permitem o acesso ao interior do estado, área coberta pela rodovia BR-364, cujo limite com o Mato Grosso fica no município de Vilhena. Pelo rio Madeira o estado faz fronteira com o município de Humaitá, no estado do Amazonas e pelo rio Guaporé o limite situa-se na localidade de Surpresa, fronteira com o Mato Grosso. O Estado também faz divisa com o estado do Acre, na área do rio Abunã, que nasce na Bolívia e corta o estado do Acre, encontrando sua foz no alto rio Madeira, em Rondônia.

Essa área iniciou a ser colonizada com base no extrativismo mineral e vegetal. Isso se deu primeiramente pela ação jesuítica, quando missionários a serviço do rei de Portugal estabeleceram aldeamentos no rio Madeira durante o século XVII. Passou desde então a ser visitado sazonalmente por expedições coletoras para a extração de produtos florestais como a salsaparrilha e o cacau e para o apresamento e escravização de indígenas. No rio Guaporé a colonização de origem portuguesa iniciou com a descoberta do ouro em 1731 e o início de sua exploração em 1734. Foi no período do governo de D. José I (1750-1777) e do seu ministro marquês de Pombal que importantes marcos da ocupação portuguesa foram estabelecidos nas regiões que hoje compõem o Norte e o Centro Oeste do Brasil. As negociações das fronteiras coloniais entre Portugal e Espanha situadas no amplo espaço que vai da linha estabelecida pelo Tratado de Tordesilhas (1494) até aqueles rios consolidaram-se em 1750, com o Tratado de Madri. Além do Tratado de Madri, foram criadas nas fronteiras dessas regiões as capitanias (atuais estados) do Mato Grosso e Cuiabá (1748) e Rio Negro (1755, hoje Amazonas).

Foi a ascensão da borracha como produto industrial que intensificou a ocupação desses rios pelos elementos nacionais e bolivianos. A extração da goma elástica atraiu, principalmente para o rio Madeira, uma grande população que ficou situada na área rural 
mas, que também fundou novas povoações com características urbanas. No rio Madeira, a Borba e Crato, povoações do século XVIII, vieram a se agregar: Manicoré, Humaitá, e Santo Antonio, ainda no século XIX. Finalmente, no alvorecer do século XX despontou a cidade de Porto Velho, que seria a futura capital do Território do Guaporé e Guajará-Mirim, no alto Madeira, como ponto final da ferrovia Madeira-Mamoré.

Mais ao norte e na mesma fronteira com a Bolívia a região do Acre foi intensamente ocupada para a extração da goma elástica. Em razão da indefinição das fronteiras entre a Bolívia e o Brasil, uma população de trabalhadores e empresários brasileiros da seringa ocupou a área e o governo do Amazonas estendeu até ali sua jurisdição. Em 1898 o governo boliviano pretendeu consolidar sua soberania sobre aquela região, instalando uma alfândega em Puerto Alonso. Segue-se então a primeira rebelião dos brasileiros, temerosos de que sua ocupação dos seringais fosse contestada pelo governo boliviano. Nos anos seguintes permaneceu a região em estado de rebelião latente ou declarada. Em 1903 foi firmado, entre o Brasil e a Bolívia, o Tratado de Petrópolis.

Nesse tratado o Brasil indenizou a Bolívia pela perda do Acre e se comprometeu a construir uma ferrovia que contornasse o trecho encachoeirado do rio Madeira. Possuindo uma extensão de mais de 300 quilômetros, esse trecho constituía um obstáculo ao comércio da Bolívia com o Brasil pela via dos rios Madeira e Amazonas. Mormente naquele momento de crescimento da demanda da goma elástica, urgia a solução do problema do tráfego por aquele trecho. A ferrovia, cuja primeira e segunda tentativas de construção foram realizadas em 1872 e 1878, ambas fracassadas, teve sua última e exitosa empresa de construção entre 1907 e 1912. A partir da construção da ferrovia, que foi denominada Madeira-Mamoré, consolidou-se o povoamento colonial da região e criou-se os elementos fundamentais para a constituição do Território Federal do Guaporé. Foi ela responsável pela criação de dois municípios no alto rio Madeira: Porto Velho, às margens do rio Madeira, que estava situado então no estado do Amazonas; e Guajará-Mirim, na ribeira do rio Mamoré, então situado no Mato Grosso.

\section{Início de vida e o ambiente político e ideológico}

Nasceu Aluizio Ferreira em Bragança, no Pará, no dia 12 de maio de 1897, quando a República Brasileira ainda passava pela sua primeira e tumultuada infância (1889 - 1930), prenunciando a tônica das demais fases. Nesses períodos de desordenada vida política os princípios de ordem e progresso inscritos na bandeira republicana brasileira somente por curtos momentos e com grande dificuldade se puderam realizar. Na Amazônia o chamado Primeiro Ciclo da Borracha representava um momento de prosperidade, alguma modernização e abundância para a elite gumífera. A modernização ficou concentrada basicamente nas cidades de Belém e Manaus e, difusamente, nas povoações do interior amazônico, representada pelo jornal, navegação a vapor e ferrovia. A abundância chegou a poucos seringueiros. Os pais de Aluízio Ferreira não dispunham de grandes posses. Eram eles Raimundo Nazareno Ferreira e Melchiades Pinheiro Ferreira. Iniciou sua alfabetização com o avô materno, completando depois o curso primário e os dois primeiros anos do curso ginasial em Belém. Em 1909 parou de estudar por falta de recursos. Em 1916 empregou-se 
na Prefeitura Municipal de Óbidos e no ano seguinte assentou praça no $4^{\circ}$. Grupamento de Artilharia. Em dezembro daquele mesmo ano viajou para o Rio de Janeiro, por motivo de doença, onde passou a servir no $2^{\circ}$. Regimento de Infantaria. Entre 1916 e 1917 serviu nesse mesmo regimento e foi promovido aos postos de anspeçada (posto militar situado entre o soldado e o cabo), cabo, $3^{\circ}$. sargento e, por fim, matriculou-se como cadete na Escola Militar de Realengo onde se formou oficial de artilharia em 1921. Daí até 1924 exerceu diversos cargos militares.

É necessário aqui abrir um parêntese para que possamos, mesmo que brevemente, estabelecer a paisagem ideológica que dominava a política brasileira a partir dos anos de 1920 e sob cujas influências Aluizio Ferreira viveu. No momento mesmo em que Aluizio Ferreira se tornou oficial, um forte movimento contrário à República, que se fizera oligárquica, já se manifestava no Brasil.

Durante a República Velha (1889-1930) podemos ainda observar a sobrevivência do Positivismo que se esmaecerá, cada vez mais apagado pela força de novas ideologias que surgirão ou penetrarão o Território Nacional. O pensamento positivista, que foi o grande paradigma da elite militar republicana nacional, será então substituído por outras formas de conceber as tarefas e a ação política no Brasil. O marechal Candido Mariano da Silva Rondon, figura de grande destaque na História Brasileira desse período e grande apoiador de Aluizio Ferreira nos seus primeiros anos de vida na área entre o Madeira e o Guaporé, foi adepto fiel dos princípios positivistas, que orientaram o Movimento Republicano. Dentre esses princípios consta o da evolução "natural" das sociedades no sentido do progresso, recusando qualquer rompimento abrupto com as instituições do passado, tal como feito no golpe republicano.

Outro movimento que surgiu nos meios militares brasileiros e tomou força após a Primeira Guerra Mundial foi denominado Tenentismo. O nome deriva da primeira graduação do oficialato, tenente, justamente o grupo das forças armadas onde o movimento possuía mais força. Surgiu no ambiente de insatisfação que se disseminou nas casernas por uma série de fatores, dentre eles: a insuficiência de investimentos em modernização do Exército e a lentidão das promoções nas patentes iniciais do oficialato. O movimento foi responsável por diversos levantes militares nos anos de 1920 como os 18 do Forte, os levantes de 1924 e a Coluna Prestes, também de inspiração tenentista. O Tenentismo combatia a corrupção generalizada do aparelho de Estado, a política do café com leite, que significava o predomínio de Minas Gerais e São Paulo no controle da política nacional. Propugnava o voto secreto (para combater o voto de cabresto, típico desse período), a independência do Poder Judiciário e um Estado mais forte. Tinha como meta geral a destruição do Estado Oligárquico implantado com a Proclamação da República.

De meados da década de 1920 ao início da década de 1930 surgiu, dentro do Estado Maior do Exército, através das figuras de Bertoldo Klinger e Góes Monteiro a defesa das Forças Armadas como garantes da política brasileira, na qual poderiam intervir em caso de grave ameaça à organização nacional. Esse conjunto de pressupostos deram força à autoimagem da juventude militar como um grupo idealista que salvaria o país das corruptas e desagregadoras práticas políticas da República Velha. 
Uma corrente política de grande penetração nos meios dos trabalhadores até os anos de 1920 foi o Anarcosindicalismo. Pretendia essa ideologia a destruição do Estado Capitalista, que definia como explorador e opressor, ao qual sucederia a sociedade livre e autogovernada. Esse movimento, responsável por importantes greves gerais em São Paulo e no Rio de Janeiro nos anos de 1910, entrou em declínio nos anos de 1920. A principal causa dessa decadência foi surgimento de um movimento concorrente de fonte Marxista, o Partido Comunista do Brasil (PCB) fundado em 1922, que passou a cooptar importantes fatias da militância anarcosindicalista. Como o Anarquismo, o Marxismo propõe à destruição violenta do Estado Capitalista, através da revolução. Diferentemente do anarquismo propõe, antes que se institua o autogoverno da sociedade, a implantação de uma Ditadura do Proletariado, destinada a extirpar da sociedade as práticas e a ideologia burguesa. Esse período de ditadura criaria a condição para o surgimento de uma sociedade autogovernada, como no Anarquismo. Muitos dos antigos adeptos do Tenentismo mudaram sua opção política no transcurso dessa década. Esse foi o caso de Luiz Carlos Prestes, tenentista e um dos líderes da Coluna Prestes, que ao retornar do exílio já se declarava marxista, passando à liderança do Partido Comunista do Brasil.

Embora organizações de viés fascista já existissem no Brasil antes de 1932 foi nesse ano que se fundou a mais importante dessas entidades a Ação Integralista Brasileira (AIB), que se tornou o maior partido nacional. O Integralismo era também uma ideologia que recusava a ideia de um governo baseado na democracia representativa tradicional. A agremiação caracterizou-se com uma organização de massa cujos filiados eram estimados em 1936 em seiscentas mil pessoas. Inspirado no fascismo italiano esse movimento, embora de carreira meteórica, foi extinto pelo governo de Vargas, durante o Estado Novo, em dezembro de 1937. Uma última manifestação do integralismo ocorreu em março do ano seguinte quando foi tentado iniciar um golpe de Estado com a tomada do Palácio Guanabara, sede do governo do Distrito Federal (então no Rio de Janeiro). Também esse movimento teve a participação de vários militares.

Assim, no Brasil da primeira metade do século XX agrupavam-se à esquerda e à direita da paisagem política adeptos, tanto civis como militares, de tradições políticas como: o coronelismo (domínio das oligarquias sobre a política), o salvacionismo tenentista, o putsch integralista, e a revolução proletária. Estava o país em uma daquelas quadras da sua história onde a percepção da superação de um quadro político já decrépito sugeria como receita a muitos o governo de exceção. Apesar do liame autoritário comum, esses movimentos produziram ações tão diversificadas em suas finalidades ideológicas como a Intentona Comunista (1935), o Levante Integralista (1938) e a própria Revolução de 1930 com o seu Estado Novo (1937-1945). Esta última sob a liderança do líder gaúcho Getúlio Vargas, cujo autoritarismo os outros movimentos propalavam combater. Os impactos sociais e políticos desses eventos chegavam a essas plagas periféricas dos estados do Amazonas e do Mato Grosso de forma bastante singular, dado o ambiente social e econômico diferenciado das regiões que lhes deram origem. É que muitos deles eram expressões dos processos de urbanização e industrialização ocorridos naqueles estados política e economicamente centrais do Brasil. 
Deste modo, no longo período que vai de 1930 até 1946, a participação do elemento militar na vida política nacional não diferia muito da participação civil, no que tange às suas diretrizes ideológicas, assim também seus comportamentos políticos. Diversos elementos oriundos do Tenentismo, um movimento político essencialmente militar, alcançaram destaque nesse período. Esse é o caso de Aluizio Ferreira na região entre o Amazonas e o Mato Grosso que viria a ser constituída como Território Federal do Guaporé.

Pelo que vimos até aqui, pode-se facilmente concluir que a resolução dos problemas nacionais era pensada pelas diversas correntes da elite intelectual nacional, de maneira geral, como necessariamente passar, na melhor das hipóteses, por um período de transição não democrático e, na pior das hipóteses como a consolidação de tipos variados de governo de inspiração totalitária. De fato, era a democracia, para os diversos grupos que concorriam ao poder nesse período, mera peça de retórica. Contribuía para esse ambiente a polarização política que impossibilitava as soluções de consenso, intermediárias e gradualistas. Resultava então desse comportamento a percepção, por parte dos principais atores do cenário político brasileiro, de que a superação do impasse seria produto de um ato de violência que eliminaria as propostas antagônicas. A proposta vencedora, que seccionou a antiga ordem e intermediou (a contragosto) o surgimento de um novo tipo de democracia (1945-1964), foi a chamada Revolução de 1930. Ironicamente esse movimento absorvia, no seu início, uma proposta de destruição da política do café com leite, bandeira típica do Tenentismo. Não havia diretivas programáticas muito claras quanto ao restante. Era contra as oligarquias dos estados de Minas Gerais e São Paulo no controle do Estado Nacional. Foi realizada com o apoio das outras oligarquias, mas agiu para apeá-las do poder através de intervenções nos estados. Sua feição ideológica foi se construindo durante todo o período de 1930 a 1945, amadurecendo ao final como Populismo.

\section{Rebelião e fuga para o vale do Guaporé}

Como já vimos, entre 1921 e 1924 Aluizio Ferreira serviu em várias unidades do Exército no Rio de Janeiro, Mato Grosso e Pará. Nesse último ano participou da rebelião tenentista, tendo seguido de Manaus (AM) com um contingente comandado pelo tenente Magalhães Barata que

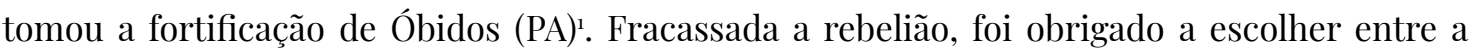
prisão e a fuga. Optou pela segunda, homiziando-se no vale do Guaporé onde permaneceu por quase três anos, de janeiro de 1925 a dezembro de $1927^{2}$. Esse é o início da vida de Aluizio Ferreira na área que hoje pertence a Rondônia. Trabalhou em seringal do coronel Paulo Saldanha, principal empresário e líder político de Guajará-Mirim à época. Prestou serviços à firma Leal e Figueiredo, aviadores da Guaporé Rubber Estate (subsidiária da ferrovia Madeira-Mamoré), até que em 1926 passou a trabalhar para o seringalista italiano Américo Casara. No ano seguinte permaneceu a serviço de Casara no seringal Laranjeira onde, certamente utilizando como apoio a bem abastecida biblioteca daquele seringalista, estudou o grupo indígena macurape.

1 Antonio José Souto Loureiro, Síntese da história do Amazonas (Manaus: Imprensa Oficial do Estado do Amazonas, 1978), 280.

2 Aluizio Pinheiro Ferreira, Uma Obra Nacionalista no Oeste do Brasil. Conferência realizada na Sociedade dos Amigos de Alberto Torres em o6 de março de 1936 (Rio de Janeiro: Typographia B. Bloch \& Irmãos, 1936), 17. 
Em 1928 entregou-se ao comando da Região Militar sediado em Belém e foi preso pela deserção resultante da rebelião de 1924. Julgado pela deserção, foi inocentado, sentença que foi objeto de recurso ao Superior Tribunal Militar que o condenou a alguns meses de encarceramento. Em janeiro de 1929 escreveu um Memorial que destinou ao marechal Rondon. Em 18 de fevereiro de 1929 encontrava-se em Belém, cumprindo a sentença a que fora condenado, quando encaminhou a Rondon o referido Memorial contendo os estudos que fizera no Guaporé3. Além das informações relativas aos índios macurapes, tecia no documento considerações relativas: à situação dos nativos em geral frente ao avanço colonizador, à guarda da fronteira com a Bolívia, questões de segurança pública, de recolhimento fiscal, de ameaças às comunidades indígenas e sugestões sobre os postos indígenas, que aconselhava merecerem maior atenção do governo central. Talvez seja esse o primeiro documento de Aluízio Ferreira onde traçou um conjunto de sugestões de políticas públicas para a região.

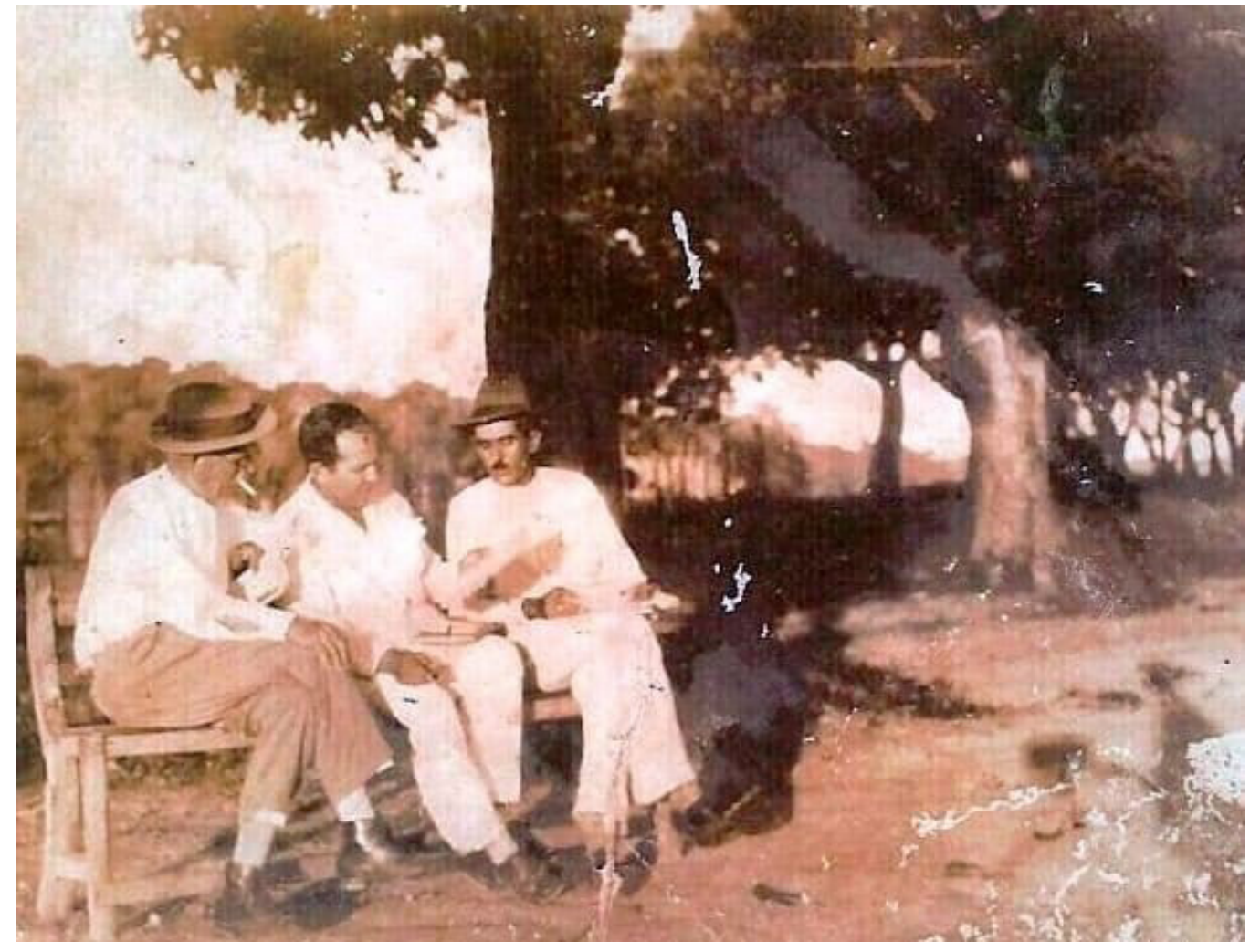

Fotografia de Aluízio Ferreira (ao centro), ladeado por Américo Casara (à direita) e um trabalhador à esquerda no seringal Laranjeira, provavelmente dos anos de 1930.

\section{Gentilmente cedida por Emanuel Fulton Madeira Casara.}

Previsto o fim de sua pena para o dia 2 de março de 1929 foi, no mesmo ano, reintegrado ao serviço ativo do Exército Brasileiro (2 de maio) e encontrou-se com o marechal Rondon no Rio de Janeiro. De Rondon recebeu o convite para que integrasse os quadros da Comissão das Linhas Telegráficas e Estratégicas do Mato Grosso ao Amazonas. Em 16 de maio apresentou-se Aluizio Ferreira ao $3^{\circ}$. Distrito Telegráfico de Mato Grosso situado na

3 Pinheiro Ferreira, Uma Obra Nacionalista, 17. 
vila de Santo Antonio, cabeça do município do Alto Madeira, que distava sete quilômetros de Porto Velho, então sob a chefia do Major Emanuel Silvestre Amarante, genro do marechal Rondon. Em janeiro de 1930 assumiu a direção daquele distrito telegráfico em razão do falecimento do titular da chefia.

Foi então que ao já conturbado quadro político nacional veio a somar, como elemento agravante, a Crise Econômica Mundial em 1929. Os grupos hegemônicos na política brasileira, as oligarquias paulista e mineira, ficaram enfraquecidos com a queda das exportações de café. A esse fato veio a somar-se as insatisfações das outras oligarquias, excluídas do poder hegemônico ao nível nacional. Em 3 de outubro do ano seguinte eclodiu a Revolução de 30. Em 3 de novembro Getúlio Vargas assumiu o governo do país como delegado da Revolução, declarando o ato em nome do Exército, da Marinha e do Povo.

Em 30 de outubro de 1930, um dos líderes revolucionários, Juarez Távora, havia declarado à imprensa que os investimentos na linha telegráfica ligando Cuiabá a Porto Velho não se justificavam, pois não satisfaziam aos critérios de importância e urgência. Em 25 de novembro de 1930 Rondon foi informado da suspensão dos serviços da Comissão das Linhas Telegráficas, ordenada pelo Ministro da Viação e Obras Públicas ao Diretor dos Telégrafos. No dia seguinte o Governo Provisório criou o Ministério dos Negócios do Trabalho, Indústria e Comércio e incorporou a ele diversas repartições públicas, entre elas o SPI (Serviço de Proteção ao Índio).

As duas instituições públicas que davam suporte, mesmo que precário, à ação de proteção ao nativo sob a inspiração de Rondon estavam então na seguinte situação: a Comissão das Linhas Telegráficas irremediavelmente extinta, caso alguma atitude contrária não fosse tomada; e o SPI passando por um processo de transferência de subordinação, viu-se depois que passageiro, a um recém-criado ministério. O cargo ocupado por Aluizio Ferreira o vinculava a Rondon através de uma teia de instituições interligadas. Havia de fato um vínculo operacional entre a Comissão das Linhas Telegráficas do Mato Grosso ao Amazonas, o Serviço de Proteção aos Índios e a Inspeção de Fronteiras ${ }^{4}$, conforme reconhecido por Rondon: "Convém salientar que a Inspeção de Fronteiras pôde realizar o programa que organizei por ser ela filha dileta da antiga comissão telegráfica, ou Comissão Rondon, como já o havia sido o Serviço de Proteção aos Índios”. Na chefia do posto telegráfico Aluizio era uma espécie de catalizador das ações dessas três entidades ao nível local. Fatos posteriores viriam a reforçar esse papel de liderança.

Embora há pouco tempo na chefia do posto telegráfico Aluizio Ferreira pôde perceber o dano que poderia causar essa política, que afetava diretamente a obra de Rondon. Segundo declarou Aluizio Ferreira, aquela foi a oportunidade de retribuir a Rondon o apoio que recebera, influenciando, como "revolucionário histórico" a manutenção dos serviços da linha telegráfica ${ }^{6}$.

4 A esse respeito vide: Ribeiro da Fonseca, “Rondon e o SPI em Guajará-Mirim (RO) na década de 1930”, em Estudos de História da Amazônia (Porto Velho: Nova Rondoniana 2014), vol. I.

$5 \quad$ Esther de Viveiros, Rondon conta sua vida (Rio de Janeiro: Cooperativa Cultural dos Esperantistas, 1969 ), 554.

6 Citado por Esron Penha de Menezes, Retalhos para a história de Rondônia (Porto Velho: Gênese, 1983), 31. 
Em 1931, ameaçaram os ingleses abandonar a concessão que detinham de exploração dos serviços da ferrovia Madeira-Mamoré em razão dos eventuais déficits e da baixa lucratividade, o que efetivamente fizeram naquele ano, suspendendo o tráfego: "A 30 de junho de 1931, às vinte e quatro horas, a 'Madeira-Mamoré Railway Company', com flagrante violação do contrato de arrendamento, abandonava a estrada de ferro e serviços anexos”. Para que o tráfego não fosse suspenso, liderou localmente Aluizio Ferreira um movimento ao final do qual a ferrovia retornou à administração do Estado Nacional. O Governo Federal através do Decreto no 20.200 de 10 de julho de 1931 resolveu que: "Art. $1^{\circ}$ O Ministério da Viação providenciará no sentido de ser restabelecido o tráfego da Estrada de Ferro Madeira e Mamoré, a qual passará a ser administrada por um diretor nomeado pelo Governo Federal" . A indicação e nomeação do primeiro diretor brasileiro da estrada de ferro contou com duas dificuldades: a) a grande distância dos centros econômicos e políticos do país e b) encontrar dentro dos quadros revolucionários pessoa qualificada para a empreitada.

Já naquele momento era a ferrovia considerada importante elemento de manutenção da colonização, de tal modo que área de abrangência ficou conhecida como Território da Madeira-Guaporé. Certamente Aluizio Ferreira, por ser militar, se enquadrava na ideia de colonização e defesa tradicionalmente requerida para a criação de um território fronteiriço desde o projeto do Visconde de Porto Seguro, Francisco Adolfo de Varnhagen (1810-1878). No "Memorial Orgânico" (1849), propunha esse autor a divisão do Brasil em 19 departamentos. O $17^{\circ}$. Departamento chamar-se-ia Madeira e sua sede governativa seria a cidade de Mato Grosso (antiga Vila Bela da Santíssima Trindade) e abrangia a área onde hoje está situado o estado de Rondônia. O departamento do Madeira uniria as partes centrais dos rios Madeira

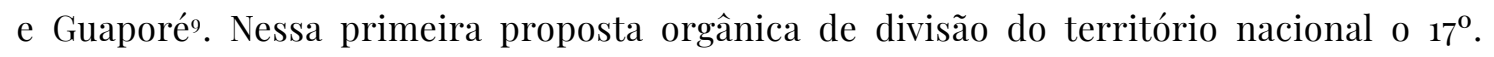
Departamento abrangia a área que seria instituído em 1943, ou seja, noventa e quatro anos depois, como Território do Guaporé.

Dada a condição fronteiriça de alguns desses departamentos, inclusive o do Madeira, deveriam ser protegidos pelo governo central e constituídos como governos militares, sendo para eles destacadas forças militares competentes e oficiais reformados. O centro da defesa militar na região seria a foz do rio Madeira no rio Amazonas (departamento do GrãoPombal), justificando essa posição em razão de incluir a defesa do rio Madeira ${ }^{10}$.

7 Pinheiro Ferreira, "A Estrada de Ferro Madeira-Mamoré”, em Os novos territórios federais (Amapá, Rio Branco, Guaporé, Ponta-Porã e Iguaçu), Geografia, História e legislação (Rio de Janeiro: Imprensa Nacional, 1946), 168.

8 Brasil - Presidência da República, "Decreto n 20.200, de 10 de julho de 1931", em Diário Oficial da União, seção 1, 14/7/1931, 11457.

9 Francisco Adolfo Varnhagen, Memorial orgânico (Brasília: FUNAG, 2016), 150.

10 Varnhagen, Memorial orgânico, 156-158. 


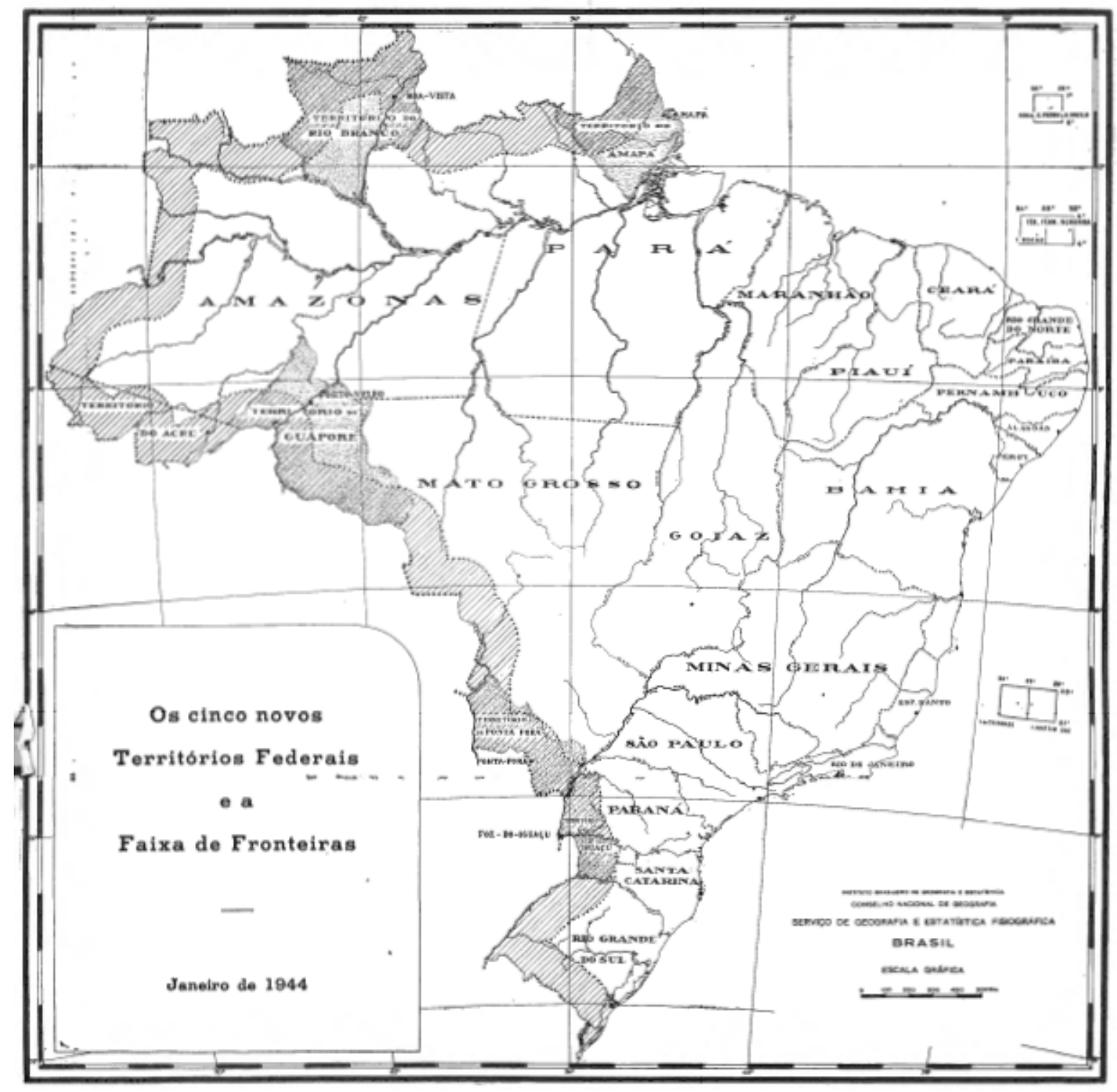

Territórios Federais em faixas de fronteiras

Fonte: Moacir M. F. Silva, "Os Territórios Federais: novo capítulo da geografia das fronteiras no Brasil”. Boletim Geográfico I, no. 10 (janeiro 1944): 34-47.

Aluizio Ferreira era militar e estava inserido nos quadros revolucionários. Além disso, mais acima vimos uma manifestação onde se declara "revolucionário histórico", por ter participado do Movimento Tenentista. Estava já radicado na região e prestara serviços à direção da Linha Telegráfica. Seria então a pessoa talhada para a tarefa e o seu nome foi, por essas razões, aventado e aceito pelo então ministro de viação e obras públicas, José Américo de Almeida, para ser o primeiro diretor brasileiro da estrada de ferro Madeira-Mamoré1. Em 1937 foi rescindido o contrato firmado entre a Madeira-Mamoré Railway Co. Ltd. e o Governo Brasileiro em $1909^{12}$.

11 Clóvis Gusmão, "Roteiro do Guaporé". O observador econômico e financeiro 107 (1944): 84.

12 Brasil - Presidência da República, "Decreto nº 1.547, de 5 de abril de 1937”. Diário Oficial da União, seção 1,

09/4/1937, 7904. 
Em 1932, durante a Revolução Constitucionalista de São Paulo, deslocou-se Aluizio Ferreira para o Rio de Janeiro onde trabalhou como oficial de ligação do gabinete do Ministro da Guerra com o Departamento do Telégrafo Nacional. Certamente estreitou e ampliou nessa oportunidade úteis laços de conhecimento com membros do novo governo. Nesse mesmo ano entregou ao Ministro da Guerra memorial onde pleiteou a criação dos Contingentes de Fronteira entre os rios Madeira e Guaporé. Em razão da instalação dessas unidades militares em Porto Velho, Guajará-Mirim e Pedras Negras (todos no território onde hoje se situa Rondônia), naquele mesmo ano tornou-se inspetor dessas unidades.

Nesse período Aluizio Ferreira tomou uma iniciativa que revelaria sua importância décadas depois. Trata-se de um formidável contributo que ajudou a constituir o estado de Rondônia. Iniciou a abrir a rodovia ligando Porto Velho a Cuiabá em 1 de agosto de 1932. A estrada foi concluída em 1961 no governo do presidente Juscelino Kubistchek como BR-29 e hoje é conhecida como BR-364.

\section{Participação na Maçonaria}

É nesse contexto de intensa atividade política e administrativa que Aluízio Ferreira foi indicado para fazer parte do quadro de obreiros Loja Maçônica União e Perseverança, número 947, em Porto Velho. Quando desse convite, já possuía dois irmãos mais novos iniciados naquela Oficina. O primeiro foi Moacyr Pinheiro Ferreira, nascido em 10 de maio de 1905. Era solteiro e funcionário público federal lotado no Contingente de Fronteira. O outro era Lourival Pinheiro Ferreira, nascido em 1 de novembro de 1899. Era casado e funcionário da ferrovia Madeira-Mamoré. Posteriormente seriam iniciados outros dois parentes: o médico Ary Tupinambá Penna Pinheiro, seu primo irmão, e o médico Rubens da Silveira Brito, seu cunhado, que foi nomeado o primeiro diretor de saúde do Território.

Na sessão do dia 29 de março de 1935 foi apresentado o pedido de iniciação de Aluizio Ferreira, que já havia beneficiado por diversas vezes a Loja que o acolheu. Em razão de suas inúmeras atividades como administrador público era obrigado a deslocar-se com certa constância para a Capital Federal, para tratar dos assuntos relativos aos trabalhos que dirigia. Assim, a sessão de Iniciação transcorreu no dia 11 de maio de 1935. Se Aluizio Ferreira já auxiliara aquela oficina nas suas beneméritas obras, a partir daquele momento sua presença tornava-se imprescindível para a continuidade dos trabalhos da Maçonaria na região. Assim é que em 13 de setembro do mesmo ano foi-lhe concedido o título de Benemérito da Loja.

\section{Inserção social e recursos de poder}

Em 1936 Aluizio Ferreira foi convidado a participar da Sociedade dos Amigos de Alberto Torres, sediada na Capital Federal. A Sociedade foi uma instituição que, embora de curta duração (1932-1945), reuniu um grupo de influentes intelectuais e homens públicos para discutir as questões relativas ao desenvolvimento do Brasil. Na palestra que proferiu naquela instituição no dia 6 de março de 1936, intitulada "Uma obra nacionalista no Oeste do Brasil”, Aluizio Ferreira relatou os acontecimentos na área da Madeira-Guaporé, destacando o trabalho das Linhas Telegráficas e Estratégicas do Mato Grosso ao Amazonas, a estatização 
da administração da Ferrovia Madeira-Mamoré, a abertura da rodovia então denominada Amazonas - Mato Grosso, os núcleos agrícolas e a colonização da fronteira, os contingentes especiais da fronteira Madeira - Guaporé. Segundo o conferencista, essas atividades tratavam, antes de tudo, de conservar a Amazônia para os brasileiros promovendo a defesa e a ocupação da fronteira, como brevemente sintetizou:

A Amazônia é a nossa máxima reserva de brasilidade, permanecerá brasileira, rebelde à cobiça das nações superpovoadas; repelindo as ambições dos povos famintos de matérias primas, de riquezas naturaes, de terras ubérrimas, desprezando as cavilosas e impatrioticas insinuações dos publicistas de nomes arrevezados [...]

Em resumo, historiou na palestra os mais importantes eventos dos quais teve marcante participação e liderança, emprestando a eles o papel de obra patriótica de desenvolvimento daquele rincão do território nacional e de defesa da Amazônia brasileira contra a cobiça internacional.

Foi a linha telegráfica, juntamente com a ferrovia Madeira-Mamoré, que delimitaram a formação do espaço onde surgiria Rondônia da seguinte forma: o eixo da ferrovia, de Guajará-Mirim a Porto Velho e desta cidade ao posto telegráfico (hoje cidade e município) de Vilhena que constituía o eixo da linha telegráfica e futura rodovia BR-364. Em um estudo sobre os territórios federais criados em 1943, ainda naquele ano sujeitos a alterações e adaptações, o Conselho Nacional de Geografia asseverou que essa unidade política teria a seguinte formação territorial: a Madeira-Mamoré como grande eixo de transportes e comunicações e a picada da linha telegráfica, futuro eixo de povoamento, deveria ser mantida dentro do Território até o posto telegráfico de Vilhena ${ }^{13}$, como de fato ocorreu.

Os eventos historiados na Sociedade dos Amigos de Alberto Torres foram importantes para a futura vida política de Aluizio Ferreira. É de se notar que através da liderança que neles revelou foi investido de grande poder político, principalmente no que se refere à ferrovia. Era a ferrovia uma espécie de segunda municipalidade, na medida em que de sua estrutura dependia parte do funcionamento de Porto Velho no que tange ao fornecimento de certos serviços públicos e mesmo do desenvolvimento da região do Madeira ao Guaporé.

O coronel Manoel Alexandrino Ferreira da Cunha, inspetor especial de fronteiras, por ordem do Estado Maior do Exército (EME) realizou em 1938 viagem de inspeção aos rios Madeira, Mamoré e Guaporé. Concluiu que os estados do Amazonas e de Mato Grosso, em razão de seus escassos orçamentos, deixavam à administração da EFMM a resolução dos problemas dos municípios sob sua jurisdição (Porto Velho, AM; Guajará-Mirim e Alto Madeira, MT) com seus próprios recursos e com a mão de obra disponível nos contingentes de fronteira. Afirma o coronel Cunha: "O capitão Aluizio Ferreira, diretor dessa ferrovia, estende também sua autoridade sobre toda a região e seus habitantes. Interfere até sobre atos sociais dessa gente: casamentos, festas públicas e esportivas”ㄴ.

13 Océlio Medeiros, A administração territorial (comentários, subsídios e novas leis) (Rio de Janeiro: Imprensa Nacional, 1946), 157-158.

14 EME - Estado Maior do Exército, Conselho de Segurança Nacional. Inspetoria Especial de Fronteiras. "Relatório (sintético)" (datilografado, 1938), 5-6. 
$\mathrm{Na}$ realidade a administração brasileira da ferrovia promoveu uma série de intervenções nas povoações do eixo ferroviário dotando-as de escolas, atendimento médico ambulante, e até mesmo auxiliando na construção de templos religiosos.

\section{Presidente de Loja em período ditatorial}

Foi durante esse período político instável ao nível nacional, mas esperançoso na região entre o Madeira e o Guaporé, que Aluízio Ferreira tornou-se maçom. Na sessão de o8 de março de 1936 Aluizio Pinheiro Ferreira foi eleito presidente da Loja Simbólica União e Perseverança. Tomou posse em 26 de setembro do mesmo ano juntamente com os demais componentes da direção.

Não encontramos as atas relativas ao período de março de 1936 a janeiro de 1937. Talvez elas sequer tenham existido em razão da intensificação das proibições do governo Vargas em relação as atividades da Maçonaria a partir daquele ano. Certamente a Intentona Comunista de 1935 e a tentativa de Golpe Integralista em 1938 foram grandemente responsáveis, ou pelo menos deram argumento, por esse tipo de reação do governo. O fato é que aproximadamente após um ano dessa eleição, 20 de maio de 1937, realizou-se a eleição de uma nova diretoria para a Loja. O livro de atas daquela Loja relativo ao ano de 1937 registra a última ata daquele ano na sessão do dia 5 de setembro. No dia 10 de novembro de 1937 foi dado o golpe que instituiu o Estado Novo. Aluizio Ferreira já havia renunciado ao cargo de presidente da Loja no dia 26 de setembro de 1938, segundo informa sua fé de ofício.

Parece esse intervalo tratar novamente da suspensão dos trabalhos da Loja, pois o mesmo livro de atas deixa de registrar as sessões em setembro de 1937 (fls. 35) reinicia os registros em agosto de 1942 (fls. 35, verso). Descarta-se nesse caso, por ser detectada a lacuna no mesmo livro de atas, a perda do livro que registraria as sessões nesse ínterim. Tudo indica que a Loja suspendeu suas atividades ou as manteve na clandestinidade, não registrando, por esse motivo, as reuniões, embora eventualmente novos documentos possam revelar outros fatos.

Esse foi um período difícil da História do Brasil, onde os Direitos Civis, dentre eles o direito à reunião, foram suspensos por mais de uma vez, particularmente após a Intentona Comunista. Constituiu esse evento na tentativa de fomentar a Revolução Comunista a partir de dois levantes: no Nordeste do Brasil em 24 de novembro de 1935 e no Rio de Janeiro em 27 de novembro de 1935. Fracassado, esse movimento forneceu a Getúlio Vargas a justificativa para decretar várias vezes nos anos posteriores o estado de sítio ou o estado de guerra.

O endurecimento das leis para o combate à subversão da ordem instituída (Constitucional mas antidemocrática) já se encontrava em andamento. Esse é o caso da Lei de Segurança Nacional de 4 de abril de 1935, que definiu crimes contra a ordem política e social. Posteriormente novas leis e mesmo três emendas à Constituição de 1934 aumentaram o poder de intervenção do Estado Brasileiro no controle das atividades políticas e sociais. Uma dessas emendas à Constituição de 1934 foi decretada em dezembro de 1935 e equiparou as situações de "comoção intestina grave" ao Estado de Guerra. Essa emenda permitiu ao Poder Executivo suspender as garantias constitucionais daquelas atividades consideradas 
prejudiciais à segurança nacional. Esse tipo de interpretação se guiava pela percepção de um "inimigo interno" que visaria subverter as instituições.

Mesmo com as principais lideranças comunistas sob cárcere, a divulgação de um suposto Plano Cohen, uma conspiração da esquerda para tomar o poder no Brasil, resultou na decretação do Estado de Guerra em 2 de outubro de 1937. Em 10 de novembro de 1937 iniciou o período denominado Estado Novo, a fase mais autoritária que impôs a ditadura até o ano de 1945. O fechamento da Maçonaria foi recomendado pelo general Newton Cavalcanti, membro do Conselho de Segurança Nacional, quinze dias após o golpe que implantou o Estado Novo $^{15}$. Segundo o historiador maçônico Frederico Guilherme Costa o governo Vargas consentiu apenas, como exceção, que a maçonaria do Distrito Federal (Rio de Janeiro) mantivesse seu funcionamento ${ }^{16}$.

\section{Uma Maçonaria dividida frente à ditadura.}

A Maçonaria Brasileira, apesar de acusada por alguns pesquisadores de participar ou ajudar a ditadura, de fato foi surpreendida em um momento difícil de sua História. As atividades associativas por ela promovidas, foram proibidas por Getúlio Vargas e encontravam-na em pleno processo de cisão iniciado em 1927. O próprio Governo Vargas era amplamente apoiado pela Igreja Católica, inimiga número um da Maçonaria naquele momento, o que tornava mais difícil a situação para a Ordem. Os interditos, que não eram somente contra a Maçonaria, buscavam guarnecer o governo Vargas ao dificultar as atividades da oposição. A percepção que temos é que em razão dessa realidade tormentosa, pela qual passava a Maçonaria, não se pode deduzir dos acontecimentos históricos transcorridos nesse período de fato um comportamento comum frente à Ditadura Vargas, aos interditos às reuniões maçônicas e face às diretrizes emitidas pelas potências jurisdicionais.

Os interditos do Período Vargas encontram a realidade do Brasil e da Maçonaria bem mais complexa que aquela do início século XIX, apresentando ao estudioso do assunto maior dificuldade de análise. O conflito básico dentro da Maçonaria no início século XIX se dava na divisão que causava as propostas separatistas e de manutenção da união com Portugal, que antecederam ao processo de Independência do Brasil. Reconhecida a impossibilidade da segunda proposta, em razão da insistência das Cortes de Lisboa em fazer o Brasil voltar ao sistema colonial, passou-se a um acirrado combate, principalmente entre as propostas de apoio à Monarquia Absolutista de D. Pedro II contra a pretensão do estabelecimento de uma Monarquia Constitucional e, no limite, a instauração do sistema republicano, que também tinha seus adeptos dentro da Ordem. Além disso, em 1822, as Lojas espalhadas pelo Brasil eram em muito menor número, não existiam em todas as províncias e havia uma só potência, o Grande Oriente do Brasil. Essa situação era mais variada na Era Vargas. Havia então potências concorrentes: uma ao nível nacional e potências regionais criadas com o Cisma de 1927.

15 José Castellani, História do Grande Oriente do Brasil: a Maçonaria na História do Brasil (Brasília-DF: Gráfica e Editora do Grande Oriente do Brasil, 1993).

16 Frederico Guilherme Costa, Questões controvertidas da Arte Real (Editora Maçônica “A Trolha” Ltda. Londrina, 1998), vol. 4 . 
A chamada cisão de 1927 foi um terrível momento para o corpo da Maçonaria Brasileira. Esse processo da divisão da Maçonaria em potências concorrentes ocorrido em 1927 não demorou a produzir suas consequências também no Amazonas. Em assembleia realizada em 24 de junho de 1927, venceu a posição favorável a criação de uma potência regional. Naquela mesma assembleia o Grande Oriente do Amazonas foi transformado em Grande Oriente do Amazonas e Acre, assumindo-se como potência regional, independente do Grande Oriente do Brasil, sob os auspícios e aliado ao Soberano Supremo Conselho do Rito Escocês Antigo e Aceito.

O número de lojas alcançava então dezenas em alguns estados brasileiros, mesmo nos estados mais interiores. Totalizava então na parte da Amazônia Legal relativa aos estados do Amazonas e Mato Grosso vinte e oito lojas, que somadas à Loja Bolívar de Cobija (BO) perfaziam vinte e nove lojas. As lojas então existentes na área do atual estado de Rondônia ao tempo dos fatos que estudamos eram: União e Perseverança (Porto Velho - 1918), Segredo e Lealdade (Presidente Marques ou Abunã - 1922) e Fé e Confiança (Guajará-Mirim - 1926). Na primeira, a dissenção provocou uma situação interna que culminou com a renúncia do presidente da loja. Foi empossada uma nova diretoria para o período 1927/1928, A Augusta e Respeitável Loja Simbólica União e Perseverança optou por acatar os Supremo Conselho, desvinculando-se do Grande Oriente do Brasil. As duas outras lojas situadas onde hoje é Rondônia fizeram o mesmo. Havia a esperança, mesmo no Grande Oriente do Brasil que a cisão seria logo superada, mas ao contrário as divergências se tornaram mais agudas nos anos imediatamente seguintes ao Cisma ${ }^{17}$.

Após a criação desse Grande Oriente Regional, em 1927, o Grande Oriente do Brasil somente iniciaria a restabelecer suas bases no Amazonas e Acre a partir de 1934, com a criação da Loja Capitular Unificação Maçônica (Manaus). Somente em 1956 haveria a reincorporação da Loja União e Perseverança ao Grande Oriente do Brasil através de ato datado do dia 26 de dezembro assinado pelo Grão-Mestrado Geral da Ordem, Dr. Cyro Werneck de Souza e Silva (decreto $\mathrm{n}^{\mathrm{o}}$ 1-771 de 26 de dezembro de 1956).

\section{Reações ao Estado de Exceção}

No que tange à Maçonaria, a percepção de sua posição política homogênea naquela primeira quadra do século XX é falsa. Não era homogênea como não foi homogênea no Processo de Independência do Brasil. Não podemos confundir hegemonia, representada pelas diretrizes emitidas pelas potências, com homogeneidade no comportamento das lojas e potências regionais.

A Era Vargas surpreende a Maçonaria em um período de divisão em potências que, naquele momento, eram rivais: o Grande Oriente do Brasil e as Grandes Lojas. E é assim dividida que a Ordem conviverá com a Ditadura Vargas. Lojas serão fechadas e as atividades maçônicas serão proibidas por decreto governamental de 1937, sob o pretexto que a doutrinação comunista pudesse encontrar guarida no sigilo das reuniões maçônicas. O

17 Mario Verçosa, Registros Maçônicos (Manaus: Imprensa Oficial do Estado do Amazonas, 1985), 85-88. 
apoio a Vargas, condição para o retorno de suas atividades foi uma dura imposição que não encontrou o consenso na Lojas e nos quadros de obreiros da instituição ${ }^{18}$.Era essa época, como vimos, de grande confusão e acirrada luta ideológica, que se refletiam na Maçonaria Brasileira, objeto de desconfiança e interditos do Regime Ditatorial. As reações dentro da Maçonaria a essa hostilidade do regime então vigente foram diversas. Intentavam em sua maioria, contudo, conciliar aquele momento com a sobrevivência da ordem, tendo o cuidado de não açular mais a animosidade do regime. Assim é que, nessa mesma época, o Grão-Mestre do Grande Oriente do Brasil publicou o Decreto no. 1.179 de 02 de junho de 1938 que exigia das Lojas Maçônicas a eliminação dos "[...] Obreiros que professassem ideologias contrárias ao regime político social brasileiro” ${ }^{19}$.

Ao que tudo indica, essa correspondência se referia especificamente aos movimentos de inspiração nazista e fascista, nesse último caso particularmente o Integralismo, embora também se pudesse referir ao Comunismo. Deve-se ressaltar que essa tendência de repúdio às tais ideologias contrárias ao regime político brasileiro era anteriores já ao decreto citado. Era notória a queda de Vargas, e de muitos dos seus aliados, pelos regimes de extrema direita naquele momento. Assim é que, conforme consta na da sessão econômica da Loja Maçônica União e Perseverança datada de 31 de maio de 1935, a leitura da circular de número 314 de 05 de maio daquele ano que declarava:

[...] ser incompatível com o ideal da Maçonaria o credo que actualmente se alastra sobre o paiz com a denominação de "Integralismo" pelo que, deve ser dado o Quit Placet ao maçom que adoptar essa doutrina bem como pesquisar a respeito à aceitação dos iniciandos.

Não é informada nessa ata qual o emissor da circular, certamente o Grande Oriente do Amazonas e Acre, que era então a autoridade jurisdicional sobre a Loja com poder para emitir esse tipo de ordem.

Nessa circular, a Potência nada mais faz que explicitar a necessidade de coerência de todo maçom com as bases doutrinárias da Ordem. A Ditadura Vargas era incompatível também com essas bases doutrinárias mas, era impensável resistir a ela sem causar sérios prejuízos à Maçonaria, tal o grau de perseguição e violência do regime. Essa é a razão pela qual, de uma maneira geral, as lojas acataram os interditos mas, algumas utilizaram-se de expedientes diversos para se reunir. Outro exemplo desse cuidado em preservar a ordem encontramos na correspondência de 16 de setembro de 1938 do Grande Oriente do Amazonas e Acre ao irmão Benedicto Pio Correa Lima, secretário da Loja União e Perseverança. Nele, onde consta uma interessante orientação, após outro interdito de dois meses às sessões maçônicas informa: "[...] não deve ser permitida a admissão daqueles que alimentam ideias extremistas, que visam a subversão dos destinos da pátria.”

Esses procedimentos ocorriam também em outras lojas, assim é que na ata de 13

18 Tiago Wolfgang Dopke, "Nosce te ipsum: sociabilidade maçônica na Revista Consciência" (Dissertação em Mestre em História, Universidade Federal da Grande Dourados, 2011), 38.

19 Costa, Questões controvertidas da Arte Real, 73. 
de novembro de 1943 foi levado ao conhecimento da Loja União e Perseverança que a Loja Esperança e Porvir de Manaus: “[...] excluiu de seu quadro irmão João Facundo do Valle, por ser ele adepto fervoroso de doutrinas subversivas e votar ao mais completo abandono os trabalhos da Of. em que recebeu a luz."

De fato, a perseguição política durante o Estado Novo era temível. Mas isso não explica totalmente a submissão da Ordem, ou de parte dela, ao regime ditatorial. É necessário acrescentar que: “[...] tínhamos Maçons apoiando o regime, até mesmo incentivando-o através de Atos que exigiam das Lojas a eliminação dos Obreiros que professassem ideologias contrárias ao regime político-social brasileiro [...]”2o. De outro modo, podemos afirmar que além da Cisão de 1927, os anos de 1930 encontram já uma Maçonaria Brasileira em avançado estado de mudança de identidade. Basta observarmos que no conjunto das obras sobre a História da Maçonaria no Brasil e constataremos que o rol das realizações políticas da Ordem termina com a Proclamação da República (1889). Nos anos de 1930 já a Maçonaria Brasileira havia concentrado seu interesse no estudo e prática da Moral contida nos seus ritos e simbolismo e na atividade de beneficência. O estudo das atas da Loja União e Perseverança revelaram que pouquíssimos eventos políticos foram discutidos em loja, embora haja a possibilidade de que pudessem ser discutidos após as sessões.

Vemos então que Aluízio Ferreira assumiu a direção da Loja União e Perseverança quando iniciava o pior momento de perseguição do governo Vargas contra a Maçonaria, ou seja, às vésperas do Estado Novo. Ao que a documentação que pudemos examinar indica, em parte desse período a Loja União e Perseverança deixou de se reunir. Coincide esse período exatamente com a eleição de Aluizio Ferreira para dirigir a Loja em 1936 e sua reeleição no ano seguinte, culminando com seu pedido de exoneração em 26 de setembro de 1938. Teria Aluizio Ferreira encontrado dificuldades em conciliar as determinações do regime ao qual apoiava com as reuniões maçônica? Dois dias depois, em 28 de setembro de 1938, o Grande Oriente do Amazonas e Acre avisou ao irmão Benedicto Pio Correa Lima, secretário da Loja União e Perseverança haver informado por correspondência de 17 de setembro de 1938 ao irmão Aluizio Ferreira que após "[...] onze longos meses de inação [...]" foram reiniciadas as atividades maçônicas. Mas as sessões não reiniciaram com a prontidão que esperava o missivista e em 28 de setembro de 1938, no mesmo dia que Aluizio Ferreira pediu a exoneração da direção da Loja, nova correspondência foi enviada do Grande Oriente do Amazonas e Acre para a Loja União e Perseverança. Nela acusava a percepção de certo desânimo em reiniciar os trabalhos da Loja e perguntava: "O que estará passando na 'União e Perseverança', sempre considerada a vanguardeira do nosso ideal?” Em 25 de novembro de 1938 foi expedida nova correspondência do Grande Oriente do Amazonas e Acre, também para o irmão Benedicto Pio Correa Lima, Secretário da Loja União e Perseverança informando que após longos meses impedidos em suas atividades estava sendo agora "[...] comunicada a ordem de funccionamento e reabertura dos nossos trabalhos Maçônicos [...]”. Qual foi a diretoria que sucedeu aquela eleita tendo como cabeça Aluizio Ferreira? Não sabemos. De fato, da administração 1937/1938 os registros da Loja saltam para a administração 1943/1944. É possível novamente aqui supor a perda de registros.

20 Costa, Questões controvertidas da Arte Real, 76. 
Do exposto pode-se deduzir que a atividade da Loja União e Perseverança ou reduziuse ou cessou momentaneamente por um período considerável. Contudo, como veremos adiante, Aluizio Ferreira continuou a servir com seu trabalho a região e a manter boas relações com a Maçonaria. Nunca foi interventor, pois a área sobre a qual tinha enorme influência política pertencia aos estados do Amazonas e Mato Grosso. Mas a direção da ferrovia Madeira-Mamoré e os outros cargos que exercia davam-lhe certa capacidade de governar informalmente a região, pois possuía mais recursos para prover as populações que os governos municipais, abandonados por seus governadores. No entanto esse poder, e apesar de seu apoio ao governo Vargas, não há registros que tenha perseguido a Maçonaria ou quaisquer dos irmãos de Loja, conforme podemos depreender dos fatos subsequentes.

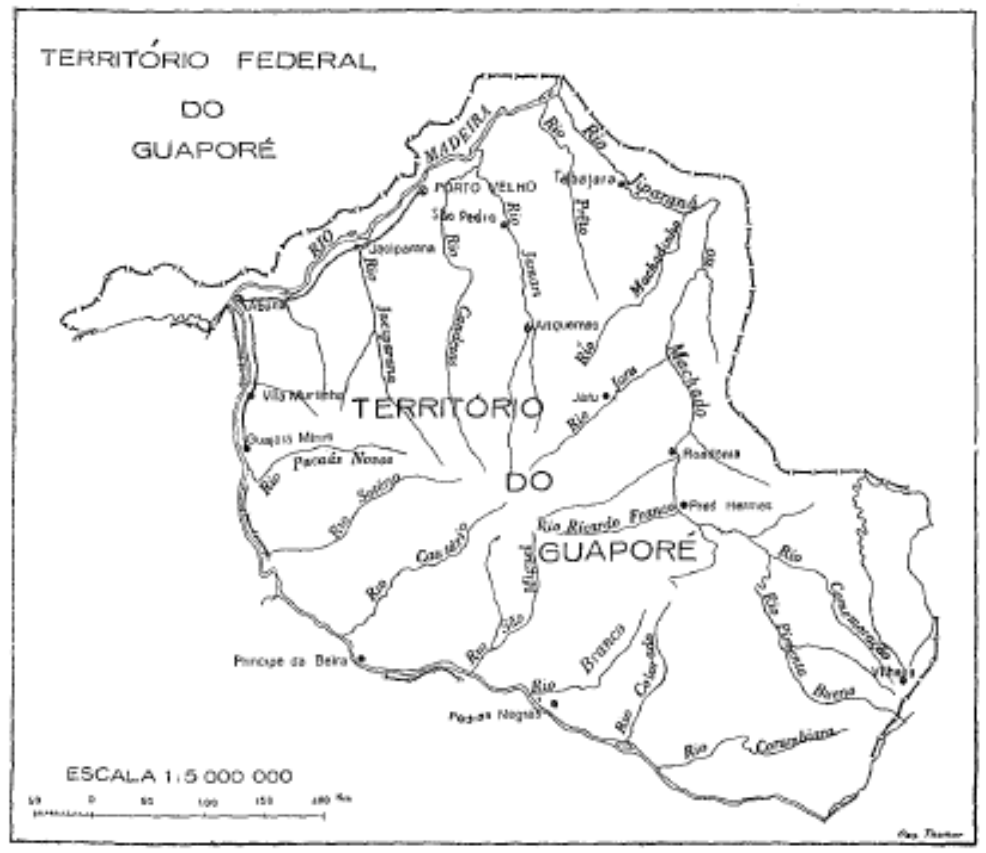

Território Federal do Guaporé em 1944.

Fonte: Antônio Teixeira Guerra, “Observações Geográficas sôbre o Território do Guaporé”, Revista Brasileira de Geografia XV, no. 2 (abril-junho de 1953): 184.

No ano de 1939 teve início a Segunda Guerra Mundial que envolveu o Brasil e a Amazônia. Marcadamente a partir de 1942, em razão dos Acordos de Washington o Brasil participou do esforço de guerra norte-americano, reativando a produção de goma elástica tão necessária às indústrias do país aliado. A discussão iniciada por Varnhagen prosseguiu, entrou pelo século XX e adquiriu novo impulso nas quatro primeiras décadas daquele século. A criação de cinco territórios federais em 1943 foi um ato do regime de exceção, de difícil consecução caso funcionasse o parlamento. Os estados não queriam perder fatias dos seus territórios, como prova a extinção de dois Territórios criados em 1943, Ponta Porã e Iguaçu, quando da nova constituinte democrática de 1946. Em 13 de setembro de 1943 foi criado o Território Federal do Guaporé, sendo Aluizio Ferreira, pela liderança demonstrada em quase duas décadas de trabalho na região, nomeado seu governador. Desse seu primeiro governo participaram inúmeros Maçons. 
O envolvimento de Aluizio Ferreira com a Maçonaria do Guaporé revestia-se de bom relacionamento como demonstra a ata de 13 de outubro de 1943 onde:

O Ven. Mestre comunica à casa que tendo, em nome da Loja, dirigido um telegrama de congratulações ao eminente e digno irmão Aluizio Ferreira pela creação do Território Federal do Guaporé, cuja feliz realização deve-se na sua maior parte aos incansáveis esforços empregados por ele.

Em reconhecimento de seu papel no importante evento, antes, em 7 de abril de 1943 , foi entregue o diploma de Grande Benemérito concedido pela Loja a Aluizio Ferreira.

Nos anos seguintes continuou ainda Aluizio Ferreira na vida política do Guaporé, tornando-se Deputado Federal em 1947, 1950 e 1960, mas já residia no Rio de Janeiro. Em 1964 se afastou da política vindo a falecer no Rio de Janeiro em 1980.

\section{Fontes consultadas}

Loja Maçônica União e Perseverança, número 947, Porto Velho, Rondônia, Brasil.

Livros de Atas correspondentes às sessões econômicas e pasta de documentos

Atas de: o6 de junho de 1927 a 10 de setembro de 1928.

Atas de: o1 de outubro de 1927 a 20 de junho de 1930.

Atas de: 17 de outubro de 1928 a 10 de julho de 1930.

Atas de: 22 de agosto de 1932 a 15 de setembro de 1933.

Atas de: 9 de setembro de 1933 a 20 de julho de 1934.

Atas de: 27 de julho de 1934 a 6 de março de 1936.

Atas de: 7 de janeiro de 1937 a 14 de abril de 1943.

Atas de: 21 de maio de 1943 a 1 de dezembro de 1943.

Pasta de documentos e correspondências recebidas entre 1938 e 1951

Fé de ofício dos obreiros: Aluizio Pinheiro Ferreira, Ary Tupinambá Penna Pinheiro, Lourival Pinheiro Ferreira, Moacyr Pinheiro Ferreira e Rubens da Silveira Brito

\section{Bibliografia}

Ávila Júnior, Celso Jaloto. A Maçonaria Baiana e sua história. Salvador, BA: P. \& A Editora, 2000.

REHMLAC+, ISSN 1659-4223, vol. 12, no. 2, diciembre 2019 / junio 2020 
Azevedo, Moreira de. "Sociedades fundadas no Brazil desde os tempos coloniaes até o começo do actual reinado". Revista Trimensal do Instituto Historico, Geographico Brasileiro e Ethnographico do Brazil (1885), tomo LXVIII, parte II, 265-322.

Bloch, Marc. Apologia da História, ou o Ofício do Historiador. Tradução de André Telles. Rio de Janeiro: Jorge Zahar Editor, 2002.

Borzacov, Yêdda Pinheiro. Aluízio Pinheiro Ferreira, 1897-1997. Porto Velho: Secretaria de Cultura, Esportes e Turismo de Rondônia, 1987.

Brasil - Presidência da República. Decreto $n^{0} .1 .547$, de 5 de abril de 1937. Declara rescindido o contrato com a Madeira-Mamoré Railway Co. Ltda. aprovado pelo decreto n. ${ }^{\circ} 7.344$, de 25 de fevereiro de 1909. Diário Oficial da União, seção 1, 09/4/1937, 7904.

Brasil - Presidência da República. Decreto $\mathrm{n}^{0}$ 20.200, de 10 de julho de 1931. Manda restabelecer o tráfego na Estrada de Ferro Madeira e Mamoré e dá outras providências. Diário Oficial da União, seção 1, 14/7/1931, 11457.

Cantanhede, Antônio. Achegas para a história de Porto Velho. Manaus: sessão de Artes Gráficas da Escola Técnica de Manaus, 1950.

Carvalho, Willian Almeida. "Pequena História da Maçonaria no Brasil”. REHMLAC 2, no.1 (maionovembro 2010): 30-58. https://revistas.ucr.ac.cr/index.php/rehmlac/article/view/6609/6298

Castellani, José. A ação secreta da Maçonaria na política mundial. São Paulo: Editora Landmark, 2002.

Castellani, José. História do Grande Oriente do Brasil: a Maçonaria na História do Brasil. Brasília-DF: Gráfica e Editora do Grande Oriente do Brasil, 1993.

“Constituição política do Império do Brasil de 1824". Collecção das Leis do Imperio do Brasil de 1824. Rio de Janeiro: Imprensa Nacional, 1886.

"Lei de 20 de Outubro de 1823: revoga o Alvará de 30 de Março de 1818 sobre Sociedade Secretas”. Collecção das Leis do Imperio do Brasil de 1823. Rio de Janeiro: 1823.

Costa, Frederico Guilherme. 2uestões controvertidas da Arte Real. Volume 4. Londrina PR: Editora Maçônica “A Trolha” Ltda., 1998.

Dopke, Tiago Wolfgang. "Nosce te ipsum: sociabilidade maçônica na Revista Consciência". Dissertação em Mestre em História, Universidade Federal da Grande Dourados, 2011.

Estado Maior do Exército - EME. Conselho de Segurança Nacional. Inspetoria Especial de Fronteiras. Relatório (sintético). Manoel Alexandrino Ferreira da Cunha (cel., inspetor de fronteiras), 1938. 
Ferreira, Aluizio Pinheiro. "A Estrada de Ferro Madeira-Mamoré". Em Os novos territórios federais (Amapá, Rio Branco, Guaporé, Ponta-Porã e Iguaçu), Geografia, História e legislação. Rio de Janeiro: Imprensa Nacional, 1946.

Ferreira, Aluízio Pinheiro. "Em Prol do Guaporé (Memorial ao Exmo. Sr. General RONDON) - Janeiro de 1929”. Em Compêndio de história e cultura de Rondônia. Porto Velho: FUNCER, 1995,.

Ferreira, Aluizio Pinheiro. Uma Obra Nacionalista no Oeste do Brasil. Conferência realizada na Sociedade dos Amigos de Alberto Torres em o6 de março de 1936. Rio de Janeiro: Typographia B. Bloch \& Irmãos, 1936.Fonseca, Dante Ribeiro da. "Aluízio Pinheiro Ferreira e Joaquim Vicente Rondon: a primeira sucessão no governo do Território Federal do Guaporé (1946)”. Fornal Eletrônico Gente de Opinião (12 de fevereiro de 2019). https://www.gentedeopiniao. com.br/colunista/dante-fonseca/aluizio-pinheiro-ferreira-e-joaquim-vicente-rondon-aprimeira-sucessao-no-governo-do-territorio-federal-do-guapore-1946

Fonseca, Dante Ribeiro da. Em Abunã nasceu a luz: a A.R.L.S. União e Perseverança número 947, cem anos de história (1918-2018). Porto Velho: Nova Rondoniana, 2018.

Godoy, Arnaldo Sampaio de Moraes. "O estado de exceção na experiência constitucional brasileira”. Revista de Estudos Constitucionais, Hermenêutica e Teoria do Direito 8, no. 3 (setembro-dezembro 2016): 286-302. https://doi.org/10.4013/rechtd.2016.83.03).

Grande Loja Maçônica de Rondônia. Augusta e Respeitável Grande Benfeitora da Ordem Loja Simbólica Fé e Confiança No o1. https://www.glomaron.org.br/o1-fe-e-confianca).

Guerra, Antônio Teixeira. "Observações Geográficas sôbre o Território do Guaporé". Revista Brasileira de Geografia XV, no. 2 (abril-junho de 1953).

Gusmão, Clóvis. "Roteiro do Guaporé”. O observador econômico e financeiro 107 (1944).

“Loja Maçônica Cayrú no. 762100 Anos de Glórias ao G.A.D.U.”. Rio de Janeiro, 2005. http:// www.cayru.com.br/lojasbra/livros.htm

Loureiro, Antonio José Souto. Síntese da história do Amazonas. Manaus: Imprensa Oficial do Estado do Amazonas, 1978.

Maquiavel, Nicolau. O príncipe. Tradução de Maurício Santana Dias, prefácio de Fernando Henrique Cardoso. São Paulo: Companhia das Letras/ Penguin Group, 2010.

Medeiros, Océlio. A administração territorial (comentários, subsídios e novas leis). Rio de Janeiro: Imprensa Nacional, 1946.

Josué Passos de Melo. "A Igreja Pentecostal na formação de Porto Velho". Em Cristianismo e religiões de matriz africana: aspectos do sincretismo religioso em Porto Velho. Porto Velho/RO: Nova Rondoniana, 2018. 
Menezes, Esron Penha de. Retalhos para a história de Rondônia. Manaus: Imprensa Oficial do Estado do Amazonas, 1980.

Menezes, Esron Penha. Retalhos para a história de Rondônia. Porto Velho: Gênese, 1983.

Pinto, Emanuel Pontes. "A saga de Aluizio Pinheiro Ferreira”. Em Compêndio de história e cultura de Rondônia. Porto Velho: FUNCER, 1995.

Pires, Joaquim da Costa. O suposto rito de York e outros estudos. Londrina: Editora Maçônica "A Trolha” Ltda., 2000.

Prefeitura do Município de Porto Velho. "Em memória de Aluízio Pinheiro Ferreira: 18971997". Porto Velho. SEMCE, sem data.

Roquette-Pinto, Edgard. "Rondônia (Anthropologia, Ethnographia)". Arquivos do Museu Nacional do Rio de Janeiro. Rio de Janeiro: Imprensa Nacional, 1917. Volume XX.

Silva Júnior, Amílcar (Grão-Mestre do Grande Oriente de Mato Grosso do Sul). "218 anos de Maçonaria no Brasil, breves análises e comentários”. Belo Horizonte: Confederação Maçônica do Brasil, 2018. https://comab.org.br/uploads/potencia/documentos/9.pdf

Silva Neto, Antônio Horácio da. "Um passeio pela história da maçonaria em Mato Grosso". Circuito Mato Grosso. http://circuitomt.com.br/editorias/cidades/120559-um-passeiopela-historia-da-maconaria-em-mato-grosso.html

Silva, António Delgado da. Collecção da Legislação Portugueza - desde a última Compilação das Ordenações - Legislação de 1811 a 1820. Lisboa: Typographia Maigrense, 1825.

Silva, Jorge Antonio Peixoto e, Dante Ribeiro da Fonseca. Preleções sobre os aspectos litúrgicos, ritualísticos e históricos da Maçonaria Simbólica. Porto Velho: Grande Oriente Estadual de Rondônia, 2007. 1 ed.

Silva, Moacir M. F. “Os Territórios Federais: novo capítulo da geografia das fronteiras no Brasil”. Boletim Geográfico I, no. 10 (janeiro 1944): 34-47.

Souza, Patrícia Inês Garcia de. "Buscadores do sagrado: as transformações da maçonaria em Belém do Pará”. Tese de Doutoramento, Universidade Estadual de Campinas, 2006.

Varnhagen, Francisco Adolfo. Memorial orgânico: (uma proposta para o Brasil em meados do século XIX). Com ensaios introdutórios de Arno Wehling. Brasília: FUNAG, 2016.

Verçosa, Mario. Registros Maçônicos. Manaus: Imprensa Oficial do Estado do Amazonas. 1985.

Vieira, David Gueiros. O protestantismo, a maçonaria e a 2uestão Religiosa no Brasil. Brasília: Unb, 1980.

Viveiros, Esther de. Rondon conta sua vida. Rio de Janeiro: Cooperativa Cultural dos Esperantistas, 1969.

REHMLAC+, ISSN 1659-4223, vol. 12, no. 2, diciembre 2019 / junio 2020 